\title{
THE STUDY OF THE EFFECT OF ETHICAL CLIMATE ON THE UNIVERSITY STUDENTS' EDUCATIONAL ATTITUDES IN OPERATING ROOM
}

\author{
NAZANINYOUSEFIAN MIANDOAB ${ }^{1}$, SADEGH ZARE ${ }^{2 *}$, MAHNAZSHAHRAKIPOUR ${ }^{3}$
}

${ }^{1}$ Department of Nursing, Community Nursing Research Center, Pregnancy Health Research Center, Zahedan University of Medical Sciences, Zahedan, Iran. ${ }^{2}$ Department of Nursing, Student Scientific Research Center, Zahedan University of Medical Sciences, Zahedan, Iran. ${ }^{3}$ Department of Biostatistics and Epidemiology, School of Health, Pregnancy Health Research Center, Zahedan University of Medical Sciences, Zahedan, Iran. Email: zaresadegh93@yahoo.com

Received: 26 April 2016, Revised and Accepted: 30 June 2016

\section{ABSTRACT}

Objective: Health-care students should be properly trained to be able to solve the society problems in the future. One of the factors affecting the academic progress of students is student's educational attitudes that are affected by the factors such as their learning environment's climate. The aim of the current study is studying the ethical climate on the university students' educational attitudes in the operating room of the medical science university in Zahedan.

Methods: In this descriptive-analytical study, the students were selected by census method (62 students). To collect the data, a three-part questionnaire was used that the first part was related to the demographic features, the second part was related to the educational attitude, and the third part was related to Olson's standard questionnaire. The data were analyzed in SPSS 19 by statistical tests, t-test, and variance analysis.

Results: The average age of students was $21.65 \pm 1.63$ and 36 participants were female and 26 participants were male. 34 participants were educating in semester 4 and 28 participants were educating semester 8 . The average score of educational attitude was $87.01 \pm 9.20$ and the average score of ethical climate was $15.58 \pm 92.85$, and the significant relationships were observed between the ethical climate and educational attitude ( $\mathrm{p}=0.03$ ).

Conclusion: The results of this study showed that students have a positive view of their field of study and existence ethical climate and managers, and officials should try to maintain this situation, and the relationship between the ethical climate and educational attitude was significant.

Keywords: Educational attitude, Ethical climate, The university students, Operating rooms.

(C) 2016 The Authors. Published by Innovare Academic Sciences Pvt Ltd. This is an open access article under the CC BY license (http://creativecommons. org/licenses/by/4. 0/) DOI: http://dx.doi.org/10.22159/ajpcr.2016.v9s2.12433

\section{INTRODUCTION}

The health-care students should be properly trained to be able to solve the society problems in the future properly $[1,2]$. One of the factors affecting academic progress of the students is the students' attitude of their field of study that today due to the wrong choice in the field of the study and consideration of the individual characteristics; most students do not have a positive attitude in their field of the study [3]. According to the study by Ashtyani et al., about $12 \%$ of medical science students are contingent at least one term during the education so that this educational failure damages a lot to the society, students, and families [4]. As well as Bahar et al. concluded that nearly a quarter of the young population is at risk of academic failure [5]. Several factors affect education attitude of the students that the ethical climate governing hospitals can be considered as one of the factors affecting the students' tendency increase to participate in clinical learning $[6,7]$ and consequently affecting their educational attitude [8-10].

The ethical climate in therapy environment is defined as a psychological structure that by employees as a result of common, consistent, and meaningful perceptions are perceived [11-13]. Researchers believe that improving the ethical environment in the health-care institutions leads to better respond to the ethical tensions and is also the cause of job dissatisfaction [14] and increasing work efficiency [15]. In this regard, Shirey stated that creating a good and acceptable ethical climate leads to improve organizational commitment and train committed workforces [16] so that if appropriate ethical climate will be observed, job interestedness among the personnel will increase and the intention of job leaving will decrease which are two important factors for the hospitals [17]. Other evidence also confirms the impact of the ethical climate on job satisfaction and interestedness $[18,19]$, organizational commitment [20,21], job rotation [22], leadership styles, decisionmaking process, and ethical judgment among the personnel and the students [23].

Without the doubt, having the positive attitude is guaranteeing success in any field of study [24]. Abdollahzadeh et al. in their study found that in according to the negative ethical climate of operating rooms from the perspective of students, most of them have a positive attitude in their field of study [25]. Attitude as the most important social-psychology concept that is defined as a combination of beliefs and emotions allocates a special place to itself in the conducted researches. According to the study conducted by Lambert, among the medical students in the United Kingdom in 2001, only 4\% of the graduated students with positive attitude showed desire to continue their studies [26,27]. While et al., in 2008, concluded that health-care universities' students in Isfahan have positive attitudes in their field of study and future career [28]. In this regard, due to the students are of the main elements in the universities, providing job satisfaction from the field of study is a factor effecting mental health and academic progress [29] and considering their beliefs and opinions is important as an acceptable tool to evaluate the quality of education [30-32]. So that if exact and logical reasons of negative attitude are not recognized, the crisis of manpower shortage in the field of health care and loss of financial, time, and energy resources are threatening [33], whereas the lack of nurse and job leaving by the nurses is one of the major problems in the developed countries such as Iran; according to statistics in Iran in $2008,90,026$ nurses are working in Iran, whereas 2,20,000 nurses are 
needed and one of the today's challenges in the health-care organization is maintaining the committed nurses [34].

Due to the effects of ethical climate on students and their educational attitudes and a few studies have been down in this field in the country, a study with the aim of studying the effect of ethical climate on the educational attitude of students in the operating room of the medical science university in Zahedan was conducted.

\section{METHODS}

This study is descriptive-analytical that is examined the attitudes of the students who educating in semester 4 and 8 in operating room of Zahedan in their field of study and the existence ethical climate in educational hospitals in Zahedan in 2014. Sampling is done by census (62 participants). The criterion of the entrance to this study was the students who started education at least on years ago and were not transferred or guest students. To collect the data a three-part questionnaire was used. The first part was related to demographic features (age, gender, education semester, and ethnicity) and second part was related to educational attitude which was designed by Abdollahzadeh et al. and its validity had confirmed and its reliability was calculated by two methods Cronbach's alpha (0.8) and intragroup correlation (0.8) [8]. The questionnaire included 26 items and responding to each item in this questionnaire were using Likert's 5 degrees scale (Strongly disagree $=1$, disagree $=2$, no comment $=3$, agree $=4$, and strongly agree $=5$ ). The scores range from 26 to 130 was divided. Then, according to the range of scores, the average was calculated 78 and accordingly, the scores lower than 78 is considered as a negative attitude and the scores higher than 78 is considered as a positive attitude. The third part included standard questionnaire on ethical climate which was designed by Olson, in 1998, and included 26 items in five areas as colleagues (4 items), doctors ( 6 items), hospital ( 6 items), patients ( 4 items), and managers (6 items). Individuals' perception of ethical climate in operating rooms was measured in five levels (Almost never $=1$, rarely $=2$, sometimes $=3$, often $=4$, and always $=5$ ) using Likert scale. Thus, the minimum possible total score for everyone was 26 and that of maximum was 130 and the scores 78 and higher than 78 as a positive ethical climate and scores lower than 78 as a negative ethical climate were considered. The questionnaire was translated into Persian by et al. by 2004 and its reliability is 0.92 [35]. To collect the data, the researcher went to the students' classes and after explaining the aim of the study and getting permissions, distributed the questionnaires and collected the questionnaire after completing them by the students. The participants were not the guest student or transferred student, and because of that, all the students were examined. The data were analyzed in SPSS 19 software by statistical tests, variance analysis, and t-test.

\section{RESULTS}

In general, 62 students participated in this study that their average age was $21.65 \pm 1.63$, and 36 participants were female $(58.1 \%)$ and 26 participants were male (41.9\%). As well as 24 participants (38.7\%) were Baloch, 20 participants (32.3\%) were from Sistan, and 18 participants (29\%) were county; and 34 participants $(54.8 \%)$ were educating in semester 4 and 28 participants (45.2\%) were educating in semester 8 . The average score of educational attitude was $9.20 \pm 87.01$ and the average score of ethical climate was $15.58 \pm 92.85$, and there was a significant relationship between the ethical climate and educational attitude $(\mathrm{p}=0.03)$. There wasn't any significant relationship between age, gender and ethical climate $(\mathrm{P}=0.05)$ Also there wasn't any significant relationship between age, sex and educational attitude $(\mathrm{P}>0.05)$. There was not a significant relationship between the educational semester, age, and ethnicity with educational attitude ( $p>0.05)$, but there was a significant relationship between the gender and ethical climate $(p=0.01)$. The female students who were studying in semester 8 had more appropriate attitude to their field of study.
There was not a significant relationship between the variables of age, gender, and educational semester with perceived ethical climate ( $p>0.05$ ), but the relationship between the ethnicity and ethical climate was significant $(p=0.03)$ and among the ethnicities, Sistanians had a better perception of the ethical climate and their field of study.

\section{DISCUSSION}

The results of this study showed that the relationship between ethical climate and educational attitude was significant. In the study by Abdollahzadeh et al. [25], the results were the same. It seems an environment where the students are trained, and the way of treatment and personnel's relations can be effective in their attitudes in relation to their field of study, because in the future after educating they should work in such an environment and spend half of their life in such an environment. However, in the study by Abdollahzadeh et al., the students had a negative perspective of ethical climate, but they had a positive perspective of their educational attitude.

The results indicated that the students had a positive view of their field of study and the ethical climate in which was in line with the results by Mobarakabadi et al. [36]. The lack of mutual respect and trust among the personnel causes to tarnish the dignity of the parties from the perspective of medical and nursing students that may cause to negative view of students' attitude to the medical profession as a factor. When the relationship among the personnel improves and the nurses' duties are clear, participated decision-making and finally their work value will be perceived well, the students will have more motivation for staying in their field of study and continuing their studies and when the students interested in their fields of study, this interest could improve students' academic progress or inversely, cause to frustration and hopelessness and feeling of tiredness from continuing education.

In this study, there was not also significant relationship between the age and gender with the ethical climate and educational attitude perceived by the students which was similar to the studies by Bahrami et al. [37] and Borhani et al. [10], but in the study by Fazljoo et al. [38], a significant relationship was observed between the gender and perceived ethical climate which was inconsistent with results of this study. Females had also better view of the ethical climate and their field of study which was consistence with the results of study by Pugh which was conducted in 2015 [39] but was inconsistent with the study by Jamali et al. which was conducted in Ghazvin [3], and the results are contrary in the study by Jamali.

The noticeable point in the results of this study is that by increasing the students' educational semester; they more interested in their field of study that was inconsistent [24] with the studies by Ghaderi et al. [24] and Abdollahzadeh et al. [25]. Perhaps, one of the reasons for this positive attitude among the students was because of ensuring their job future due to lack of manpower in the health-care organization $[34,38]$ that was approved in the study by Ghaderi et al. [24]. However, according to Weiner's theory [40], they stated that the basic factor to progress is intrinsic motivation, and it can be concluded that if an important field such as medicine is selected due to less important reasons such as situation and economic issues and due to selecting spouse or parents' view, continuing this way and being successful will be less observed.

\section{CONCLUSION}

The results of this study showed that the students have a positive view of their field of study and the existence ethical climate, and the managers and officials should try to maintain this situation and the relationship between the ethical climate and educational attitude of students was significant. One limitation of this study was because of the high number of the questionnaire's questions that the students did not complete carefully and was also not considering to factors affecting educational attitude such as: Individuals' satisfaction of clinical training, their place of residence, as well as how the manner of evaluating by professors. It 
is recommended that in other studies by considering these factors and other effective factors, obtain better results.

\section{ACKNOWLEDGMENT}

This study was the result of a student research project approved at Zahedan University of Medical Sciences. Hereby, we express our deep gratitude to those people who participated and collaborated in this study and research authorities of Zahedan University of Medical Sciences who helped us in the process of data collection and financial support.

\section{REFERENCES}

1. Rjali M, Mostajeran M, Lotfi M. Health student attitude towards their field of study and future career in health faculty of Isfahan university of medical sciences-2008. Sci Res J Health Syst Res 2010;6(1):106-15.

2. Miandoab NY, Arbabisarjou A, Zare S, Shahrakipour M. Surgical technology students' attitude toward their field of study. Der Pharm Lett 2015;7(12):25-9.

3. Jamali HA, Ghalenoei M. Attitudes of environmental health and occupational health students toward their discipline and future career in Qazvin university of medical sciences in 2012. IranJ Med Educ 2013;13(7):541-50.

4. Ashtyani SC, Shamsi M, Mohammadbeygi A. Frequency of educational decline and some effective factors of student's opinion in Arak university of medical sciences, 2009. Arak Med Univ J 2010;12(4):24-33.

5. Bahar HH. The effects of gender, perceived social support and sociometric status on academic success. Procedia-Soc Behav Sci 2010;2(2):3801-5.

6. Midgley K. Pre-registration student nurses perception of the hospitallearning environment during clinical placements. Nurse Educ Today 2006;26(4):338-45.

7. Rahimi A, Ahmadi F. The obstacles and improving strategies of clinical education from the viewpoints of clinical instructors in Tehran's nursing schools. Iran J Med Educ 2005;5(2):73-80.

8. Andrews M, Wallis M. Mentorship in nursing: A literature review. J Adv Nurs 1999;29(1):201-7.

9. Duffy K, Docherty C, Cardnuff L, White M, Winters G, Greig J. The nurse lecturer's role in mentoring the mentors. Nurs Stand 2000;15(6):35-8.

10. Borhani F, Jalali T, Abbaszadeh A, Haghdoost AA, Amiresmaili M. Nurses' perception of ethical climate and job satisfaction. J Med Ethics Hist Med 2012;5:6.

11. Miandoab NY, Arbabisarjou A, Zare S, Shahrakipour M, Bradang N. Operating room staff attitude toward the ethical climate of educational hospitals. Der Pharm Lett 2015;7(12):122-5.

12. Jahantigh M, Arbabisarjou A, Zare S, Shahrakipour M, Ghoreishinia G. Hospital's ethical climate and nurse's desired ethical climate in Ali-ebnAbitaleb and Khatam-al-Anbia hospital of Zahedan (2015). Der Pharm Lett 2015;7(12):427-31.

13. Joolaee S, Jalili HR, Rafii F, Hajibabaee F, Haghani H. The relationship between ethical climate at work and job satisfaction among nurses in Tehran. Indian J Med Ethics 2013;10:238-42.

14. Schluter J, Winch S, Holzhauser K, Henderson A. Nurses' moral sensitivity and hospital ethical climate: A literature review. Nurs Ethics 2008;15(3):304-21.

15. McDaniel C. Ethical environment: Reports of practicing nurses. Nurs Clin North Am 1998;33(2):363-72.

16. Shirey MR. Ethical climate in nursing practice: The leader's role. JONAS Healthc Law Ethics Regul 2005;7(2):59-67.

17. Chonko LB, Wotruba TR, Loe TW. Direct selling ethics at the top: An industry audit and status report. J Personal Selling Sales Manage 2002;22(2):87-95

18. Goldman A, Tabak N. Perception of ethical climate and its relationship to nurses' demographic characteristics and job satisfaction. Nurs Ethics
2010;17(2):233-46

19. Schwepker CH Jr. Ethical climate's relationship to job satisfaction, organizational commitment, and turnover intention in the salesforce. J Bus Res 2001;54(1):39-52.

20. Delgoshaei B, Tofighi S, Kermani B. The relationship between organizational climate and organizational commitment in teaching hospitals of Hamedan university of medical sciences. Horiz Med Sci 2009; 14(4):60-8.

21. Mulki J, Jaramillo J, Locander W. Effect of ethical climate on turnover intention: Linking attitudinal-and stress theory. J Bus Ethics 2008;78(4):559-74.

22. Hart SE. Hospital ethical climates and registered nurses' turnover intentions. J Nurs Scholarsh 2005;37(2):173-7.

23. Huerta SR. Mission and Hospital Ethical Climate as Perceived by Nurses. Chicago: Pro Quest; 2008.

24. Ghaderi R, Dastjerdi R, Sorush Z, Mouhebati M. Influential factors in medical students attitudes towards studying medicine in 2002. Iran J Med Educ 2003;3(2):47-55.

25. Abdollahzadeh F, Lotfi M, Mirzaaghazadeh A, Asl ZE. Ethical climate of operating rooms and its relationship with students attitudes towards their field of study in teaching hospitals of Tabriz university of medica sciences in 1393. Iran J Med Ethics Hist Med 2015;7(5):94-104.

26. Lambert TW, Goldacre MJ, Davidson JM, Parkhouse J. Graduate status and age at entry to medical school as predictors of doctors' choice of long-term career. Med Educ 2001;35(5):450-4.

27. Rajagopal S, Rehill KS, Godfrey E. Psychiatry as a career choice compared with other specialties: A survey of medical students. Psychiatr Bull 2004;28(12):444-6.

28. Rejali M, Mostajeran M, Lotfi M. Health student a attitude towards their field of study and future career in health faculty of Isfahan university of medical sciences - 2008. Health Syst Res 2010;6(1):106-15.

29. Arasteh M, Hadinia B, Sdaghat A, Charajo N. Assessment of mental health status and its related factors among medical and non medical staff in the hospitals of Sanandaj city in 1385. Sci J Kurdistan Univ Med Sci 2008;13(3):35-44

30. Baykal U, Sokmen S, Korkmaz S, Akgun E. Determining student satisfaction in a nursing college. Nurse Educ Today 2005;25(4):255-62.

31. El Ansari W, Oskrochi R. What matters most? Predictors of student satisfaction in public health educational courses. Public Health 2006;120(5):462-73.

32. El Ansari W. Student nurse satisfaction levels with their courses: Part I -- Effects of demographic variables. Nurse Educ Today 2002;22(2):159-70.

33. Jolaee S, Mehrdad N, Bahrani N. The investigation of nursing students' opinions about their profession and the reasons for its withdrawal in medical scienses universities in Tehran. Iran J Med Educ 2006;1(1):21-8.

34. Borhani F, Jalali T, Abbaszadeh A, Haghdoost A. Nurses' perception of ethical climate and organizational commitment. Nurs Ethics 2014;21:278-88.

35. Mobasher M, Nkhaee N, Garoosi S. Assessing the ethical climate of Kerman teaching hospitals. Iran J Med Ethics Hist Med 2008;1(1):45-52.

36. Mobarakabadi A, Shamsi M, Najafianzadeh M. Health student attitude towards their field of study and future career in health faculty of Arak university of medical sciences, Iran. J Strides Dev Med Educ 2014;11(2):280-5.

37. Bahrami MA, Taheri G, Montazeralfaraj R, Tafti AD. The relationship between organizational climate and psychological well-being of hospital employees. World J Med Sci 2013;9(1):61-7.

38. Pugh GL. Perceptions of the hospital ethical environment among hospital social workers in the United States. Soc Work Health Care 2015;54(3):252-68

39. Fazljoo E, Borhani F, Abbaszadeh A, Razban F. The relationship between nurses' perceptions of moral distress and the ethical climate in Shahid Sadoughi university of medical sciences of Yazd. Iran J Med Ethics Hist Med 2014;7(2):80-90.

40. Weiner B. The role of affect in rational (attributional) approaches to human motivation. Educ Res 1980;9(7):4-11. 